\title{
Human reliability assessment (HRA) in maintenance of production process: A case study
}

\author{
Mojgan Aalipour ${ }^{1}$, Yonas Zewdu Ayele ${ }^{2}$, Abbas Barabadi ${ }^{2 *}$ \\ ${ }^{1}$ Division of Operation and Maintenance Engineering, Luleå University of Technology, Luleå, \\ Sweden \\ ${ }^{2}$ Department of Engineering and Safety, UiT The Arctic University of Norway, Tromsø, \\ Norway
}

\begin{abstract}
Human reliability has a high contribution in maintenance performance, safety, and cost efficiency of any production process. To improve human reliability, the causes of human errors should be identified and the probability of human errors should be quantified. Analysis of human error is very case specific in which the context of the field should be taken into account. The aim of this study is to identify the causes of human errors and, improve human reliability in maintenance activities in cable manufacturing industry. The central thrust of this paper is to employ the three most common HRA techniques - HEART (Human Error Assessment and Reduction Technique), SPAR-H (Standardized Plant Analysis Risk-Human Reliability), and BN (Bayesian Network) for estimating human error probabilities, and then to check the consistency of results obtained. The case study results demonstrated that the main causes of human error during maintenance activities are time pressure, lack of experience, and poor procedure. Moreover, the probabilities of human error obtained by employing the three techniques are almost similar and consistent.
\end{abstract}

Keywords: Human error, human reliability, performance shaping factors, HEART, SPAR-H, Bayesian Network.

\footnotetext{
* Corresponding author: Abbas Barabadi, Associate Professor, UiT The Arctic University of Norway, Department of Engineering and Safety, Phone: +4777660339, Fax: +4777644900, abbas.b.abadi@uit.no
} 


\section{Introduction}

Each year billions of dollars are spending on plant maintenance and operation. The cost of maintenance and operations by American manufacturers, for instance, is over 300 billion of dollar each year. It is an alarmingly high cost of engineering systems, which can be significantly reduced by applying a human factor principle during the design and operation phase (Mannan, 2012, Castiglia and Giardina, 2013). Maintenance process of complex industrial technology is noted as being especially vulnerable to human error; and, human error have a high contribution in maintenance cost profile of production plants (Kirwan and Ainsworth, 1992). Human errors in maintenance activities may generally lead to incorrect decisions, actions, or checks (Singh and Kumar, 2015). Mannan (2012) and Castiglia and Giardina (2013) demonstrated that human error is the primary causal factor of between $50 \%$ and $90 \%$ of the accidents in industries. Hence, to reduce the consequences from human error and assure effective maintenance process, precise estimation of the potential human error and their probability of occurrences during the maintenance execution is vital. It helps to establish a plan that can ensure improved maintenance/repair procedures, workplace ergonomics as well as improved operational steps. Consequently, it increases the maintenance performance and reduces the cost of maintenance significantly.

Over the years, numerous human reliability assessment (HRA) methods and frameworks have been developed to perform a structured analysis of human reliability and human error probabilities; see e.g. Park (1987), Bell and Holroyd (2009), Akyuz and Celik (2015), Noroozi et al. (2013), De Felice et al. (2012), Zio et al. (2009), Konstandinidou et al. (2006), Bertolini (2007), and Deacon et al. (2013). In general, HRA involves the use of qualitative and quantitative methods to assess and quantify the human contribution to the risk profile (Bell and Holroyd, 2009). For instance, Bell and Holroyd (2009) carried out a literature review and, a total of 72 potential human reliability related tools are identified. Akyuz and Celik (2015) developed an approach to estimate HRA via knowledge-based system, to minimize the operational problems that may arise from human errors on-board ships. Noroozi et al. (2013) proposed a risk-based methodology for pre- and post-maintenance of a pump based on Human Error Assessment Reduction Technique (HEART). De Felice et al. (2012) investigated the state-of-the-art of the reliability analysis of human operator; and used a Technique for Human Error Prediction (THERP) for HRA. Deacon et al. (2013) implemented a combination of expert judgment techniques for evaluating the risk during the evacuation opreration. Further, Podofillini et al. (2010) proposed a fuzzy expert system (FES) formalism for dependence assessment in HRA, which captures the rules used by experts to assess dependence levels and incorporates this knowledge into an algorithm and software tool. Zio et al. (2009) suggested HRA framework, which is based on a fuzzy expert system in which a set of transparent fuzzy logic rules is used to represent the relationship between the input factors and the conditional human error probability.

However, most of the available methods are broad, all inclusive practical techniques that are developed for the nuclear industry (Bell and Holroyd, 2009, Kirwan, 1997, Kirwan, 1996). Other production process industries, such as mining industry or offshore industry will provide its peculiar challenge and its own performance-shaping factors (performance influencing factors), which can be completely different from the nuclear industry. The major question with 
such approaches is whether or not the conventional methods can provide accurate human reliability estimation for these industries. To answer this key validation question, it is vital to carry out independent validation experiment. Moreover, once a given technique achieved some degree of predictive validity, the next question becomes whether such a technique can consistently produce valid and accurate results (Kirwan, 1996). In order to validate such methods and values of human error probabilities, in general, experts' (specialists) opinions and data banks must be used.

Further, it is preeminent to execute the HRA by using more than one method and, consequently check the consistency of human error probability estimation results. Several methods have been compared and studied in the literature to check the validity and consistency of some developed HRA methods; see e.g. Kirwan (1994), Castiglia and Giardina (2013), Calixto (2012), and Kirwan et al., (1997). These studies considered both the pros and cons of HRA techniques such as SLIM (Success Likelihood Index Method), HEART, and THERP under various scenarios. For instance, Kirwan (1994) reviewed the validity of THERP, HEART and JHEDI (Justification of Human Error Data Information), which are the main HRA techniques used in the UK, to predict human performance in high risk industries. The findings from their analysis confirms the empirical validity of these techniques. Castiglia and Giardina (2013) compared the HEART and CREAM (Cognitive Reliability and Error Analysis Method) technique, by carrying out the HRA of maintenance process of refueling station of the hydrogen storage systems. The results of their comparison demonstrated that the estimated probabilities of human error are significantly close for both techniques. Further, Calixto (2012) studied some applicable HRA method for oil and gas industry and applied these methods in turbine startup. Despite applying different methodologies, Calixto (2012) found out that human error probability in turbine startup has similar behavior.

The purpose of this paper is thus to check the consistency of the three HRA methods HEART, SPAR-H, and BN (Bayesian Network), by using a cable manufacturing company as an illustrative case study. In addition, the paper identified the causes of human errors during maintenance activities in cable manufacturing industry and, the human error probabilities are computed. Further, this paper studied how an improvement in a specific factor, such as training of personnel's contributes positively on reducing the probability of human error and cost of maintenance.

The rest of the paper is organized as follows. Section 2 presents a bird eye view of the human reliability assessment techniques. Section 3 presents a description of the the case study and, the application of the HEART, SPAR-H, and BN techniques. Section 4 provides the discussion of the case study anlysis and the concluding remarks.

\section{Background - A birds eye view of human reliability assessment (HRA)}

HRA generally has three basic functions: $i$ ) the identification of human errors, ii) the prediction of their likelihood, and iii) reduction of their likelihood if required; see e.g. Swain and Guttmann (1983); Dhillon (1989); Park and Jung (1996); Kirwan (1994); and Embrey et al. (1994). Human reliability is described as the probability of humans conducting specific tasks with satisfactory performance (Calixto, 2012). Tasks may be related to equipment repair, equipment or system 
operation, safety actions, analysis, and other kinds of human actions that influence system performance. Human error is contrary to human reliability and basically, the human error probability, $P(H E)$ is described as (Bell and Holroyd, 2009):

$$
P(H E)=\frac{N_{E}}{N_{E O}}
$$

where:

- $\quad N_{E}$ represents number of errors.

- $\quad N_{E O}$ represents number of error opportunities.

In general, human error is described as the failure to implement a definite task (or performance of a not allowed action) that could result in disruption of planned tasks or damage to equipment and property. The most common reasons for human errors are counted as inadequate training and skill, poor maintenance instructions and operating procedures, poor work layout, poor equipment design and improper work tools (McLeod, 2015). Hence, to have an effective HRA, it is necessary to understand various types of human error, such as commission error, omission error, and intentional error, as well as the factors that influence them. There are several factors, which influences human error, such as internal (psychological and physiological) or external (technological and social) human performance-shaping factors (McLeod, 2015, De Felice et al., 2012).

Table 1. Summary of generation of HRA used in maintenance and operational analysis

\begin{tabular}{|c|c|c|c|}
\hline & Description & Tool & Source \\
\hline \multirow{4}{*}{ 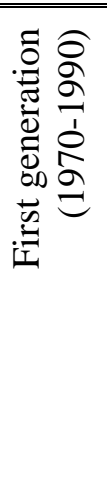 } & $\begin{array}{l}\text { It focused on human error } \\
\text { probabilities and human operational }\end{array}$ & THERP & $\begin{array}{l}\text { Kirwan (1992) } \\
\text { Lyons et al. (2004) }\end{array}$ \\
\hline & errors. & $\begin{array}{l}\text { OAT (Operator } \\
\text { Action Tree) } \\
\text { SLIM -MAUD }\end{array}$ & $\begin{array}{l}\text { Apostolakis (1985) } \\
\text { Watson (1985) } \\
\text { Noroozi et al. (2013) } \\
\text { Davoudian et al. (1994) }\end{array}$ \\
\hline & & STAH-R & $\begin{array}{l}\text { Moieni et al. (1994) } \\
\text { Swain (1990) } \\
\text { Calixto (2012) }\end{array}$ \\
\hline & & HEART & $\begin{array}{l}\text { Raouf et al. (2006) } \\
\text { Williams (1988) }\end{array}$ \\
\hline 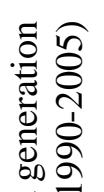 & $\begin{array}{l}\text { It focused on human performance- } \\
\text { shaping Factors( internal or externa) } \\
\text { such as workload, stress, sociological } \\
\text { issues, psychological issues, illness, }\end{array}$ & ATHEANA & $\begin{array}{l}\text { De Galizia et al. (2015) } \\
\text { Fonseca et al. (2013) } \\
\text { Čepin (2008) }\end{array}$ \\
\hline $\begin{array}{l}\widetilde{D}_{\tilde{U}}= \\
\text { के } \\
\omega\end{array}$ & etc. and cognitive processes. & CREAM & $\begin{array}{l}\text { Hollnagel (1998) } \\
\text { Kim et al. (2006) }\end{array}$ \\
\hline
\end{tabular}


It focused on human performance-

shaping factors, relations, and dependencies.
Bayesian Network

Groth and Swiler (2013)

Weber et al. (2012)

Trucco et al. (2008)

Baraldi et al. (2009)

Brooker (2011)

Williamson (2004)

One of the most challenging steps in HRA is quantification of human reliability. Human reliability data is difficult to obtain and they can be uncertain (Kirwan, 1994, Kirwan and Ainsworth, 1992). Different data can be used for quantification of human reliability including, historical records, collected data (direct or simulated), estimation techniques (constructive, comparative), judgement and experience (Taylor-Adams and Kirwan, 1997). In addition, choosing the appropriate HRA approach is another challenge. Table 1 depicts a paradigm shift and different generation of HRA for quantification of human reliability and error probabilities.

Furthermore, to decide which human reliability analysis methods to apply, it is also necessary to know about human reliability method characteristics, their objectives, and limitations. Technique selections for specific case depends on the nature of the assessment availability of data, applicability of data, ease of use (time, cost, resources, information), data validity (justification), experience of assessor and level of assessment needed are some important some criteria including (Taylor-Adams and Kirwan, 1997, McLeod, 2015).

\section{An illustrative case study: Cable manufacturing company}

In this section, different HRA techniques, specifically the HEART, SPAR-H, and BN techniques, are employed for estimating the probability of human error occurring during the maintenance tasks in a cable manufacturing company in Iran. In this company, the maintenance of extruder machines is selected as the case study. The extruder is not only one of the most important and expensive machines, but also the most accurate and technical machine in the cable manufacturing industry. For this reason, experienced and high skilled operators need to work with this machine. The main function of this machine is insulation of the electrical conductors to create a proper operational condition for transferring electricity. Failure in the extruder machines thus, leads to shut down of the production line. The gearbox is most critical part of the extruder machine and, a major proportion of failures with extruder machines are related to the gearbox (Fig. 1). Hence, estimating the probability of human errors, which occur during repair process activities of gearbox, is imperative. In general, the repair or maintenance tasks during gearbox failure are as follows:

- Step 1: Disassembly of gear box

- Step 2: Measurement and inspection

- Step 3: Corrective maintenance

- Step 4: Assembly and installation

- Step 5: Testing and final inspection 

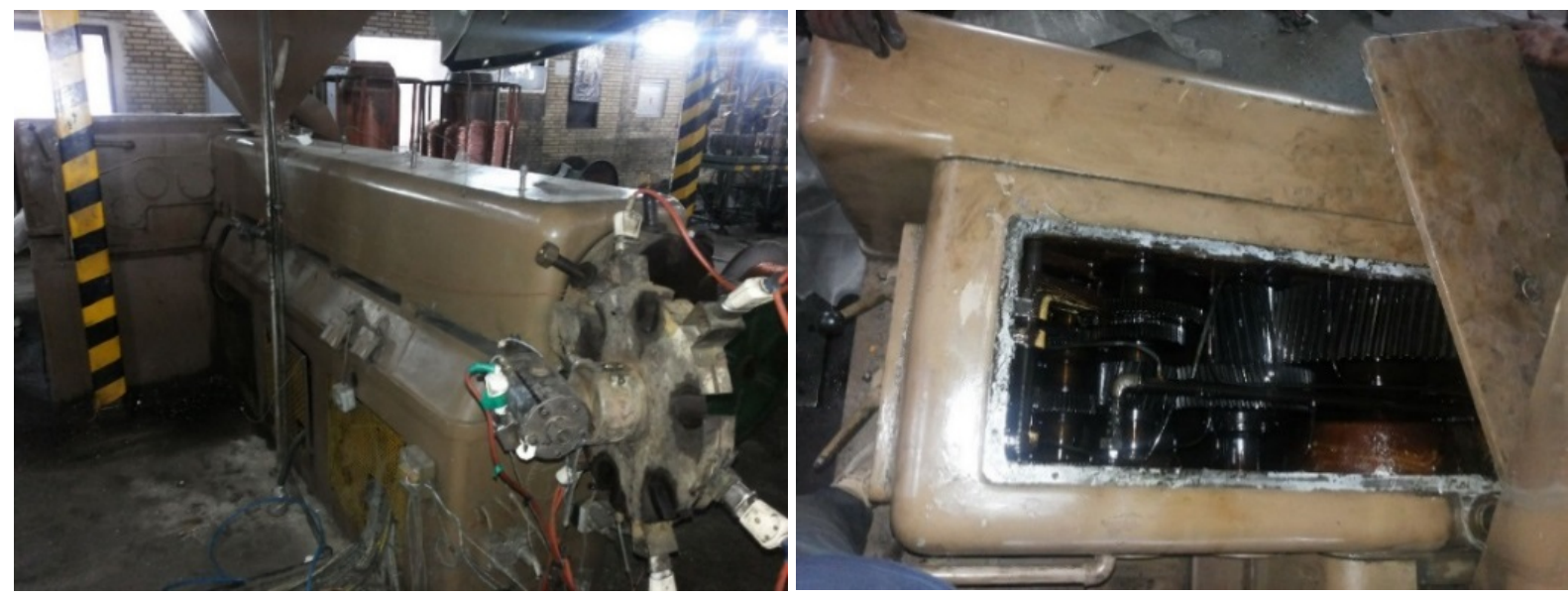

Fig. 1. Gearbox extruder machine

In the event of failure of the gearbox, the production process can be fully shutdown and, may cause damage that could take from several hours to one month to fix, depending on the severity of the damage. The extruder machines shutdown does not cause any damage to other systems; however, the economic consequences of downtime and repair process varies from $14000 \$$ to $23000 \$$ for several hours or days of extruder machines shutdown, respectively. The repair on the gearbox is conducted by a team of experienced employees and their supervisor checked the steps. In this case study, judgements provided by those people with expertise in identifying potential human errors during repair tasks are utilised at various stages of this HRA in order to estimate the probabilities of human error. In this case a formal expert judgment process is followed, which consists of three main phases, namely expert selection, elicitation of expert opinions, and aggregation of expert opinions. A number of experts' are selected and then experts' data are elicited through an individual interview. Once expert opinions are elicited, weighted-arithmetic is used as aggregation method to combine expert data and thus to obtain a single solution that will be used by the decision-makers (Meyer and Booker, 2001).

\subsection{Data collection}

Data related to the human error probabilities in the course of the maintenance tasks, during failure of the gearbox, was collected via interviews and meetings with the cable manufacturer. The data collection process has included four main phases. The first phase of the data collection rocess includes: intial (first-step) interview, documentation review, observation of the maintenance procedures, etc. In this phase, the main maintenance tasks, which are implemented during repairing of the gearbox of extruder machine has been identified and recognised. In particular, the maintenance tasks of the gearbox has been observed for six full-days in two weeks period. Moreover, several maintenance manuals, procedures, and instructions of the manufacturing company, which are applicable for repairing process of the gearbox have been studied during this phase. In the second phase, the main maintenance activities of the gearbox are classified into five main maintenance tasks and, then for each group the detailed maintenance tasks are identified. In the third phase, two focus group discussions have been conducted by including two maintenance supervisors and manager, in order to verify and finalize the main maintenance activities and sub tasks. In the fourth and final phase of the data 
collection, the human error probabilities in the course of the maintenance activities has been estimated for the each main and sub tasks via three experts' discussion. The members of the experts' consisted of two experienced operators, three maintenance supervisors as well as one plant manager. All of the three experts' discussions were undertook in the manufacturing company vicinity, by gathering the operators and the supervisors from maintenance workshop and productive line.

\subsection{Application of HEART for estimating the probability of human error}

HEART is an expert judgment technique that relies on the knowledge and experience of the assessor in relation to evaluated actions (McLeod, 2015, Calixto, 2012). Fig. 2 illustrates the HEART quantification process. In general, after defining the activity, the corresponding generic task and the nominal human unreliability should be identified. Thereafter, considering the operational condition, the error-producing condition related to the activity will be identified. By doing so, the rate of the error-producing condition can be assessed. Finally, the final human error probability will be calculated by:

$\operatorname{Final}(H E P)=G E P \times \Pi R(i) \times\left(W_{i}-1\right)+1$

where:

- HEP represents human error probability,

- GEP is generic error probability,

- $R(i)$ is the value of context task, and

- $W(i)$ is the weight for each context task.

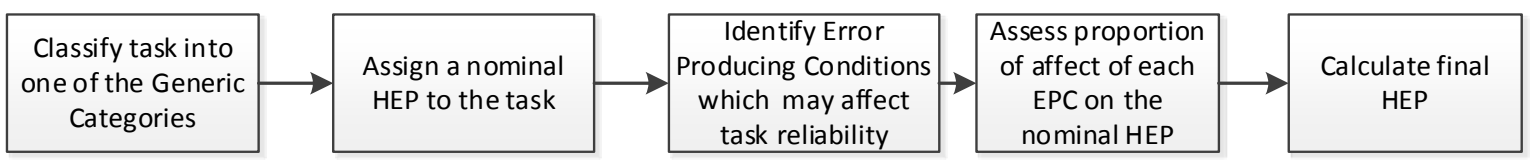

Fig. 2. HEART quantification process, adapted from (Kirwan, 1996)

As mentined above, the repair tasks of gearbox are categorised in five main maintenance tasks: disassembly of gear box, measurement and inspection, corrective maintenance, assembly and installation, and testing and final inspection. The estimated HEP of the defind tasks associated with the maintenance of a gearbox using HEART are depicted Table 1.

From the estimated results, it can be deduced that the probabilities of a human error during the disassembly and installation tasks are higher than others tasks. The total estimated HEP of maintenance tasks in the case of gearbox failure is estimated to be 0.242 , which is around $24.2 \%$. Further, from the human reliability analysis, it is identified that a shortage of available time to do the given task, operator inexperience, and a need for absolute judgments, which are beyond the capability or experiences of an operator, as a main contributor to a high level of human errors.

Hence, in order to reduce the human error probabilities from the above mentioned causes, the experts' have been asked to suggest some improvement recommendation that can be 
implemented during repair activities of a gearbox. The experts' outlined the following points, which can be helpful to improve the efficiency of the operator while performing the given task and, consequently reduce the probabilities of the human error: $i$ ) improve the procedure of the repair task, ii) establish a training program, and iii) improve the repair group coordination and communication. Thereafter, the recommendations from the experts' are implemented and, the human error probabilities after the improvements have been estimated; and, the summary of the result is shown in the last column of Table 2. The results after the improvements demonstrated that the human error probabilities in startup significantly reduced from $24.2 \%$ to $10.3 \%$. Further, the expected cost of human error during gearbox repair process, varies from $\$ 3388$ $(24.2 \% \times \$ 14000)$ to $\$ 5566(24.2 \% \times \$ 22000)$ in optimist and pessimist terms, respectively. However, these costs are significantly reduced after the reduction of HEP from 24.2\% to 10.3\%; the exact value varies from $\$ 1442(10.3 \% \times \$ \$ 14000)$ to $\$ 2266(10.3 \% \times \$ 22000)$. That means, in general, the reduction in cost as a result of the improvement varies from $\$ 1946$ to $\$ 3300$.

Table 2. Human error probability of gearbox extruder machine after and before improvement

\begin{tabular}{lcc}
\hline \hline Task & HEP & HEPimp. \\
\hline \hline A- Disassembly Tasks of Gear Box & 0.073 & 0.031 \\
B- Measurement and Inspection task & 0.020 & 0.014 \\
C- Corrective maintenance tasks & 0.042 & 0.017 \\
D- Assembly and Installation Tasks & 0.062 & 0.027 \\
E- Testing and Final Inspection Task & 0.045 & 0.014 \\
Total Human Error Probability (HEP) & $\mathbf{0 . 2 4 2}$ & $\mathbf{0 . 1 0 3}$ \\
\hline \hline
\end{tabular}

\subsection{Application of SPAR-H for estimating the probability of human error}

The main objective of SPAR-H technique is to define human error probability based on human performance factor influence. In general, estimating the probabilities of the human error using the SPAR-H techniques requires specialist opinion to define the human factors influence based on performance-shaping factor values. By employing the SPAR-H techniques, the HEP can be estimated as:

$$
H E P=\frac{N H E P \times P S F_{\text {composite }}}{N H E P\left(P S F_{\text {composite }}-1\right)+1}
$$

where:

- $\quad$ NHEP is the nominal human error probability, and

- $\quad P S F_{\text {composite }}$ is the composite Performance-Shaping Factor and is given as:

$$
P S F_{\text {composite }}=\prod_{i=1}^{n} P S F_{i}
$$


The SPAR-H method generally is based on eight performance-shaping factors (PSFs) that encapsulate the majority of the contributors to human error. These eight PSFs are as follows (Boring and Gertman, 2005): available time to complete task, stress and stressors, experience and training, task complexity, ergonomics, the quality of any procedures in use, fitness for duty, and work processes. Each performance-shaping factor feature should be listed with different levels and associated multipliers. Further, SPAR-H method establishes the value of human error probability to omission error (0.01) and commission error (0.001). However, the main challenge during HRA analysis using SPAR-H technique is understanding of the effect of the PSFs on the human reliability.

In order to conduct the SPAR-H analysis, similar group of experts' are used and estimated the human error probability values related to human failures for each tasks, from 1 to 5 . In addition, the opinions' from each operator was also considered and integrated for describing the PSFs composite. The estimated HEP as well as the PSFs composite for each task is depicted in Table 3. In general, in this analysis, the PSFs were considered to be adequate, nominal stress level, nominal complexity, poor procedure, nominal ergonomics, nominal fitness for duty, and nominal work process. Nominal means that the given PSFs are in good conditions and, have low influence on a given failure. It is obvious to observe that the PSFs do not possess the same values, since each tasks are different; and, the tasks are affected by the PSFs in dissimilar ways. For instance, Task 3 is generally more complex than Task 2.

Table 3. Performance shaping factors (PSFs) composite of a gearbox

\begin{tabular}{lccccc}
\hline \hline $\begin{array}{l}\text { PSF (Performance-shaping } \\
\text { factors) }\end{array}$ & Task 1 & Task 2 & Task 3 & Task 4 & Task 5 \\
\hline \hline Available time & 1 & 10 & 10 & 1 & 1 \\
Stress & 2 & 1 & 2 & 2 & 2 \\
Complexity & 1 & 2 & 2 & 1 & 1 \\
Experience/training & 1 & 0.5 & 0.5 & 1 & 0.5 \\
Procedures & 1 & 1 & 5 & 5 & 1 \\
Ergonomics & 1 & 1 & 10 & 1 & 1 \\
Fitness & 1 & 5 & 5 & 1 & 1 \\
Work process & 0.5 & 1 & 5 & 0.5 & 1 \\
PSF & 1 & 50 & 25000 & 5 & 1 \\
HEP & 0.001 & 0.00498 & 0.20016 & 0.00498 & 0.001 \\
\hline \hline
\end{tabular}

As mentioned above, a SPAR-H procedure recommends using 0.01 for human error probability with commission error and, 0.001 for omission error. For this particular case, the experts' supposed that the commission error is the main route of the human error, and then 0.001 is used for NHEP. The estimated HEP, by employing a SPAR-H technique, is equal to $21.2 \%$. Therafter, the experts' improvement recommendations are implmeted and, the HEP is estimated, which illustrated in Table 4. The results demonstrated that, after such improvements, the human error probabilities in startup are reduced from $21.2 \%$ to $9.5 \%$. Moreover, the expected cost of human error during gearbox repair process, varies from $\$ 2968(21.2 \% \times$ $\$ 14000)$ to $\$ 4664(21.2 \% \times \$ 22000)$ in optimist and pessimist terms, respectively. Further, these costs are significantly reduced after the reduction of HEP from $21.2 \%$ to $9.5 \%$; the exact value varies from $\$ 1330(9.5 \% \times \$ 14000)$ to $\$ 2090(9.5 \% \times \$ 22000)$. That means, in general, the reduction in cost as a result of the improvement varies from \$1638 to \$2574. 
Table 4. Performance shaping factors composite after improvement

\begin{tabular}{lccccc}
\hline \hline PSF & Task 1 & Task 2 & Task 3 & Task 4 & Task 5 \\
\hline \hline Available time & 1 & 1 & 1 & 1 & 1 \\
Stress & 2 & 1 & 2 & 2 & 2 \\
Complexity & 1 & 2 & 2 & 1 & 1 \\
Experience/training & 1 & 0.5 & 0.5 & 1 & 0.5 \\
Procedures & 1 & 1 & 1 & 1 & 1 \\
Ergonomics & 1 & 1 & 5 & 1 & 1 \\
Fitness & 1 & 1 & 5 & 0.5 & 1 \\
Work process & 0.5 & 1 & 0.090992 & 0.01 & 0.001 \\
HEP & 0.001 & 0.001 & & & 1 \\
\hline \hline
\end{tabular}

\subsection{Application of Bayesian Network (BN) for estimating the probability of human error}

Bayesian network (BN) also known as causal networks, belief networks, and probabilistic networks (PNs), is a concept for reasoning complex uncertain problems, where network means a graphical model (Lee and Lee, 2006). In general, BN can be used for three kinds of reasoning: i) causal reasoning - from known causes to unknown effects, $i$ ) diagnostic reasoning - from known effects to unknown causes, and iii) a combination of causal and diagnostic reasoning (Mihajlovic and Petkovic, 2001). BN consists of a qualitative part, a directed acyclic graph (DAG), where the nodes represent random variables and a quantitative part, a set of conditional probability functions (Marquez et al., 2010, Ayele et al., 2015). The nodes can be discrete or continuous, and may or may not be observable and the arcs (from parent to child) represent the conditional dependencies or the cause-effect relationships among the variables (Marquez et al., 2010). Parent nodes are nodes with links pointing towards the child nodes. Nodes that are not connected represent variables, which are conditionally independent of each other. The quantitative part of a BN can be represented as a product of conditional distribution of each node, $N_{i}$ given its parents nodes, parents $\left(N_{i}\right)$. Each node is described by the conditional probability function of that variable. Then, the joint probability distributions, considering discrete variable, can generally be expressed as:

$\operatorname{Pr}\left(N_{1}, N_{2}, \ldots, N_{M}\right)=\prod_{i}^{M} \operatorname{Pr}\left(N_{i} \mid \operatorname{parents}\left(N_{i}\right)\right)$

where:

- $\operatorname{Pr}\left(N_{i} \mid\right.$ parents $\left.\left(N_{i}\right)\right)$ is the conditional distribution mass function of node, $N_{i}$.

In order to estimate the HEP, in this case study, the causal dependencies among the main performance shaping factors (PSFs) are described using reasoning processes. The BN approach treats each of the PSFs as independent of the other PSFs. The BN for this case study was constructed using AgenaRisk software 6.2 revision 2650, which is a commercial generalpurpose BN software tool (AgenaRisk, 2015). Fig. 3 illustrates the original static BN fragment considering the causal dependencies between the main variables, i.e., the PSFs and HE. 


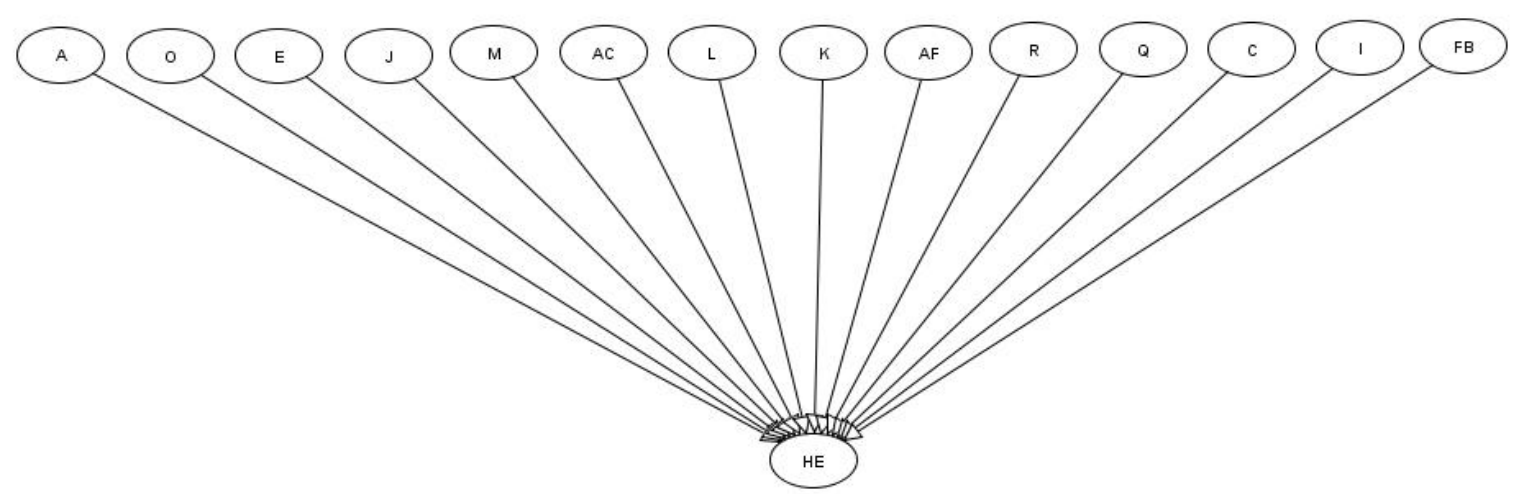

Fig. 3. Structure of the causal based Bayesian belief network

After constructing the BN, the states of discrete nodes are specified, and the relationships between the connected nodes (variables) are quantified. In general, for each particular discrete node, all possible combinations of values of those parent nodes must be observed; and such a combination is called instantiation of the parent (Korb and Nicholson, 2010). For instance, for a Boolean network, a variable with n parents requires a CPT (conditional probability table) with $2^{n+1}$ probabilities (Korb and Nicholson, 2010, Ayele et al., 2015). These probabilities can be estimated or assigned using direct elicitation and/or machine-learning techniques. For computational convenience, in this cases study, all PSFs and Human Error (HE) node were considered as Boolean nodes; and the marginal probabilities tables (MPTs) are estimated based on the direct elicitation (Korb and Nicholson, 2010) of expert judgement. Thereafter, to assign a CPT, a BN learning and probabilistic inference are carried out by employing AgenaRisk (2015). In addition, a direct elicitation technique has also used to assign a CPT; that means the CPT takes the following possible joint values:

$\left\{\begin{array}{l}\langle P(H E=T \mid A=N)\rangle,\langle P(H E=T \mid O=T)\rangle,\langle P(H E=T \mid E=S)\rangle,\langle P(H E=T \mid J=N)\rangle,\langle P(H E=T \mid M=T)\rangle,\langle P(H E=T \mid A C=F)\rangle, \\ \langle P(H E=T \mid L=F)\rangle,\langle P(H E=T \mid K=F)\rangle,\langle P(H E=T \mid A F=F)\rangle,\langle P(H E=T \mid R=F)\rangle,\langle P(H E=T \mid Q=P)\rangle,\langle P(H E=T \mid C=F)\rangle, \\ \langle P(H E=T \mid I=F)\rangle,\langle P(H E=T \mid F B=F)\rangle\end{array}\right\}$

The recognised PSFs are sorted, a MPT are assigned, and a CPT are inferred, and the result is shown in Table 5. For instance, $P(H E=T \mid A=N)$ describes the probability that the human error will occur given not sufficient allocated maintenance time. In Table 5, $P\left(\right.$ Node $\left._{i}\right)$ represents the MPT for each PSFs, which is assigned based on direct elicitation/expert judgement; $P\left(\right.$ Node $\left._{i}\right)$ imp represents the MPT after implementing improvement in all PSFs; $P\left(H E=T, F \mid N_{o d e}\right)$ represents the conditional probability of Human Error node, given the PSFs, and it is inferred by using AgenaRisk (2015) and direct elicitation; and the $P\left(H E=T, F \mid N_{\text {Node }}\right)$ imp represents the conditional probability after implementing improvement.

Table 5. The PSF, MPT, and CPT result

\begin{tabular}{|c|c|c|c|c|c|c|}
\hline Node & Description & Node states & P(Node $\left.{ }_{i}\right)$ & P(Node $)_{i}$ imp & $\begin{array}{l}P(H E=T, F \mid \\
\left.\text { Node }_{i}\right)\end{array}$ & $\begin{array}{l}\text { P(HE=T,F } \mid N \\
\left.\text { ode } e_{i}\right) \text { imp }\end{array}$ \\
\hline \multirow[t]{2}{*}{ A } & \multirow{2}{*}{$\begin{array}{l}\text { Allocated } \\
\text { maintenance time }\end{array}$} & E (sufficient time) & 0.4060 & 0.4060 & 6.09E-03 & 6.09E-03 \\
\hline & & N (not sufficient time) & 0.5940 & 0.5940 & 5.05E-02 & 5.05E-02 \\
\hline \multirow[t]{2}{*}{$\mathbf{O}$} & Overriding & $\mathrm{T}$ (overriding occurred) & 0.1585 & 0.1090 & $1.51 \mathrm{E}-02$ & 1.09E-02 \\
\hline & information & $\begin{array}{l}\text { F (overriding doesn't } \\
\text { occurred) }\end{array}$ & 0.8415 & 0.8910 & 4.21E-03 & 8.91E-05 \\
\hline $\mathbf{E}$ & Operator experience & E (extensive) ( $\geq 5$ yrs.) & 0.7525 & 0.8515 & 7.53E-03 & 5.96E-02 \\
\hline
\end{tabular}




\begin{tabular}{|c|c|c|c|c|c|c|}
\hline & & $\begin{array}{l}\mathrm{S} \text { (shallow) }(0 \text { yrs. } \leq \mathrm{E}<5 \\
\text { yrs.) }\end{array}$ & 0.2475 & 0.1485 & 2.23E-02 & 4.46E-03 \\
\hline \multirow[t]{2}{*}{$\mathbf{J}$} & \multirow{2}{*}{$\begin{array}{l}\text { Need of absolute } \\
\text { judgement }\end{array}$} & $\mathrm{R}$ (required) & 0.6040 & 0.7030 & $6.04 \mathrm{E}-03$ & 4.92E-02 \\
\hline & & $\mathrm{N}$ (not required) & 0.3960 & 0.2970 & 3.56E-02 & 8.91E-03 \\
\hline \multirow[t]{2}{*}{$\mathbf{M}$} & \multirow{2}{*}{$\begin{array}{l}\text { Mismatch b/n an } \\
\text { operator and } \\
\text { designer model }\end{array}$} & $\mathrm{T}$ (mismatch occurred) & 0.3070 & 0.1585 & $2.61 \mathrm{E}-02$ & $1.58 \mathrm{E}-02$ \\
\hline & & $\begin{array}{l}\text { F (mismatch doesn't } \\
\text { occurred) }\end{array}$ & 0.6930 & 0.8415 & $1.04 \mathrm{E}-02$ & 8.42E-05 \\
\hline \multirow[t]{2}{*}{ AC } & \multirow{2}{*}{$\begin{array}{l}\text { Acquaintance } \\
\text { (familiarity with the } \\
\text { task in-hand) }\end{array}$} & $\mathrm{T}$ (familiar) & 0.9010 & 0.9550 & $9.01 \mathrm{E}-03$ & 7.64E-02 \\
\hline & & F (unfamiliar) & 0.0990 & 0.0450 & 8.91E-03 & $9.00 \mathrm{E}-04$ \\
\hline \multirow[t]{2}{*}{$\mathbf{L}$} & \multirow{2}{*}{$\begin{array}{l}\text { Educational level vs. } \\
\text { the task requirement }\end{array}$} & $\mathrm{T}$ (matched) & 0.7030 & 0.8020 & $1.41 \mathrm{E}-02$ & 6.42E-02 \\
\hline & & F (mismatched) & 0.2970 & 0.1980 & 2.38E-02 & 3.96E-03 \\
\hline \multirow[t]{2}{*}{$\mathbf{K}$} & \multirow[t]{2}{*}{ Knowledge transfer } & $\mathrm{T}$ (without lose) & 0.8020 & 0.9010 & $2.41 \mathrm{E}-02$ & 7.21E-02 \\
\hline & & F (with lose) & 0.1980 & 0.0990 & 1.39E-02 & $1.98 \mathrm{E}-03$ \\
\hline \multirow[t]{2}{*}{ AF } & \multirow{2}{*}{$\begin{array}{l}\text { Allocation of } \\
\text { function }\end{array}$} & $\mathrm{T}$ (clear allocation) & 0.8515 & 0.9010 & $1.70 \mathrm{E}-02$ & 4.51E-02 \\
\hline & & F (unclear allocation) & 0.1485 & 0.0990 & 1.19E-02 & 4.95E-03 \\
\hline \multirow[t]{2}{*}{$\mathbf{R}$} & \multirow{4}{*}{$\begin{array}{l}\text { Reliability of } \\
\text { instrumentatio } \\
\text { Quality of } \\
\text { information }\end{array}$} & $\mathrm{T}$ (reliability) & 0.8515 & 0.8515 & $1.28 \mathrm{E}-02$ & $1.28 \mathrm{E}-02$ \\
\hline & & F (unreliability) & 0.1485 & 0.1485 & $1.26 \mathrm{E}-02$ & $1.26 \mathrm{E}-02$ \\
\hline \multirow[t]{2}{*}{$\mathbf{Q}$} & & G (good quality) & 0.8020 & 0.9010 & 1.20E-02 & 4.51E-02 \\
\hline & & $\mathrm{P}$ (poor/impoverished quality) & 0.1980 & 0.0990 & $1.68 \mathrm{E}-02$ & 4.95E-03 \\
\hline \multirow[t]{2}{*}{$\mathrm{C}$} & \multirow[t]{2}{*}{ Checking procedure } & $\mathrm{T}$ (well-structured) & 0.8020 & 0.9010 & 8.02E-03 & 7.21E-02 \\
\hline & & F (a little or no-checking) & 0.1980 & 0.0990 & $1.78 \mathrm{E}-02$ & $1.98 \mathrm{E}-03$ \\
\hline \multirow[t]{2}{*}{$\mathbf{I}$} & \multirow[t]{2}{*}{$\begin{array}{l}\text { Interpretation } \\
\text { consistency }\end{array}$} & $\begin{array}{l}\mathrm{T} \text { (consistent interpretation of } \\
\text { display) }\end{array}$ & 0.9010 & 0.9010 & 1.08E-02 & $1.08 \mathrm{E}-02$ \\
\hline & & $\begin{array}{l}\mathrm{F} \text { (inconsistent interpretation } \\
\text { of display) }\end{array}$ & 0.0990 & 0.0990 & 8.71E-03 & 8.71E-03 \\
\hline \multirow[t]{2}{*}{ FB } & \multirow[t]{2}{*}{ Feedback } & $\mathrm{T}$ (good feedback) & 0.9010 & 1.0000 & $9.01 \mathrm{E}-03$ & $5.00 \mathrm{E}-02$ \\
\hline & & F (poor/ambiguous feedback) & 0.0990 & 0.0000 & 8.91E-03 & $0.00 \mathrm{E}+00$ \\
\hline
\end{tabular}

As mentioned above, our enquiry is to get the human error probability, $P(H E)$. Hence, to estimate the causal reasoning (i.e. $P(H E)$ ), the $\mathrm{BN}$ is structured in such a way that it is possible to link together PSFs to Human Error. Thereafter, to estimate $P(H E)$, AgenaRisk (2015) as well as Eq. (7), which is inference algorithm are employed, by considering different node states. The inference result shows that the estimated human error probability, $P(H E)$ is $2.463 \mathrm{E}-01$.

$P(H E)=\sum_{P S F s} P\left(H E=T \mid\right.$ Node $\left._{i}\right)$

After implementing improvement in all of the PSFs, the P(HE)imp are estimated using AgenaRisk (2015), which equals 1.04E-01. The result of analysis shows after improvements, the human error probabilities in startup reduced from $24.63 \%$ to $10.04 \%$. Considering the cost of repair and down time the expected cost of human error when gearbox are under the repair varies from 3448 $(24.63 \% \times \$ 14000)$ to $\$ 5418(24.63 \% \times \$ 22000)$ in optimist and pessimist terms, respectively. After improvement, for $10 \%$ human error probability the expected cost of human failure varies from $\$ 1400(10 \% \times \$ 14000)$ to $\$ 2200(10 \% \times \$ 22000)$. The reduction in cost varies from $\$ 2048$ to $\$ 3218$.

\section{Discussion and concluding remarks}

This work has employed the three most common human reliability analysis techniques HEART, SPAR-H, and BN for estimating the human error porobabilities during maintenance activities in a cable manufacturing company. The employed techniques are checked against the consistency criteria. Further, the illustrative case study analysis results demonstrates that despite applying different HRA techniques, the estimated human error probabilities in gearbox 
has possess similar behavior with small differences in value. This basically demonstrates that the employed techniques are good enough to perform human reliability analysis, by considering various performance-shaping factors. Fig. 4 illustrates the estimated HEPs before and after implementing the improvement for each HRA tools - HEART, SPAR-H, and BN.

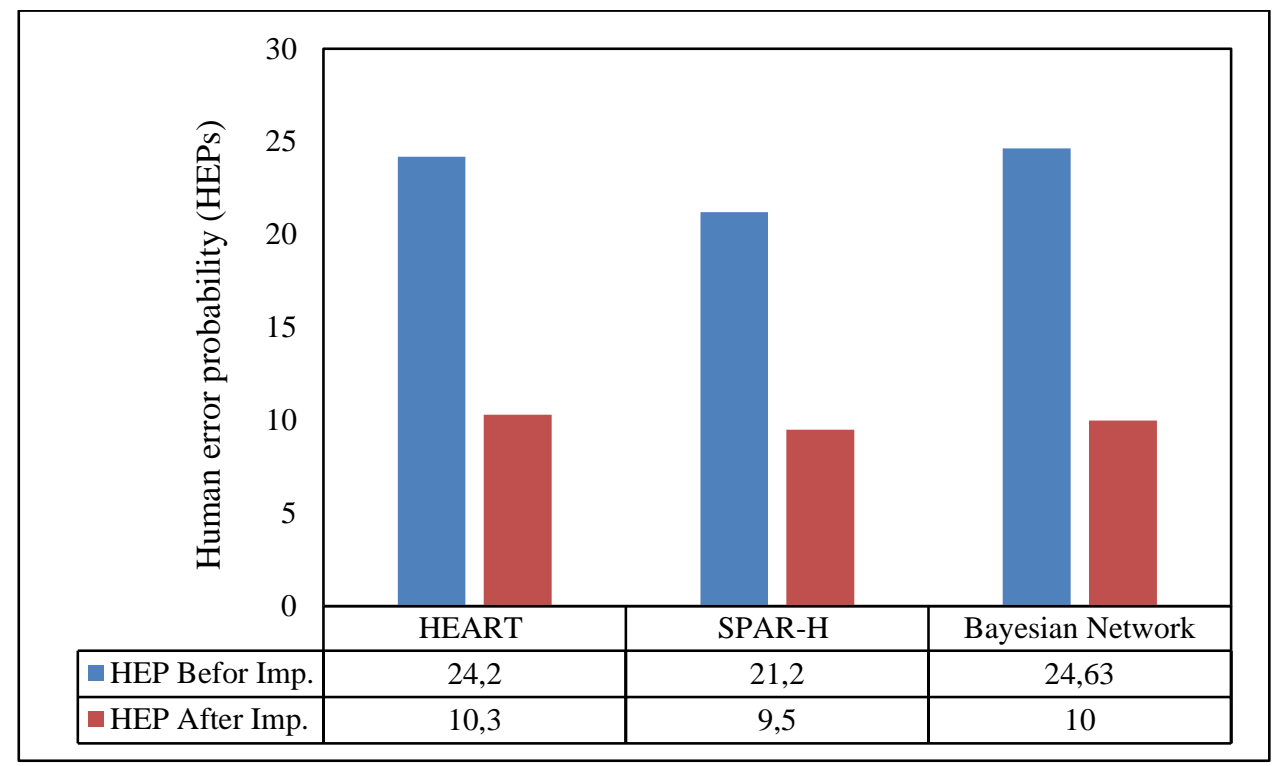

Fig. 4. The estimated HEPs before and after implementing the improvement

The concluding remarks are as follows:

- The HEPs estimation analysis results showed that in the course maintenace activities, the HEPs before implementing improvement is between 2.232 to 2.463 times greater than that of HEPs after the improvement.

- The effect of implementing improvement on the cost element results is between $\$ 1638$ to $\$ 3218$ less than that of the cost element before implementing the improvement.

Our conclusion is that proper estimation of human error probabilities as a key part of HRA will result in more efficient maintenace operation. A shortage of historical probability of human error occurrence data, for different maintenace tasks, was an issue during the illustrative case study analysis. Therefore, the results should be interpreted in light of the current state of knowledge about maintenace tasks in cable manufacturing industry. Moreover, the resulting human error probability values from the illustrative case study analysis should be updated as new data/evidence becomes available, preferably in the form of field (hard) data reflecting the actual operational experience in the cable manufacturing industry and, therefore gradually supplanting the opinions elicited from experts. Moreover, it is imperative to evalute the given HRA analysis tools in different case study scenarios, for checking their effectiveness, to support strategic decision. Further, the critical analyses of the obtained results can also allowed to provide procedural recommendations and suggestions regarding safety equipment and procedures, which can be adopted to reduce the risk of accidents.

\section{References}


AGENARISK. 2015. Agena - Bayesian netwok and simulation software for risk analysis and decision support [Online]. Available: http://www.agenarisk.com/ 2015].

AKYUZ, E. \& CELIK, M. 2015. Computer-Based Human Reliability Analysis Onboard Ships. Procedia-Social and Behavioral Sciences, 195, 1823-1832.

APOSTOLAKIS, G. 1985. On the assessment of human error rates using operational experience. Reliability engineering, 12, 93-105.

AYELE, Y. Z., BARABADY, J. \& DROGUETT, E. L. Risk assessment of Arctic drilling waste management operations based on Bayesian Networks. Safety and Reliability of Complex Engineered Systems: ESREL 2015, 2015 Zurich, Switzerland. CRC Press 1907-1915.

BARALDI, P., CONTI, M., LIBRIZZI, M., ZIO, E., PODOFILLINI, L. \& DANG, V. A Bayesian network model for dependence assessment in human reliability analysis. Proceedings of the Annual European Safety and Reliability Conference, ESREL, 2009. 223-230.

BELL, J. \& HOLROYD, J. 2009. Review of human reliability assessment methods. Health and Safety Laboratory, United Kingdom.

BERTOLINI, M. 2007. Assessment of human reliability factors: A fuzzy cognitive maps approach. International Journal of Industrial Ergonomics, 37, 405-413.

BORING, R. L. \& GERTMAN, D. I. Advancing usability evaluation through human reliability analysis. Proceedings of HCI International 2005, 2005.

BROOKER, P. 2011. Experts, Bayesian Belief Networks, rare events and aviation risk estimates. Safety Science, 49, 1142-1155.

CALIXTO, E. 2012. Gas and Oil Reliability Engineering: Modeling and Analysis, Gulf Professional Publishing.

CASTIGLIA, F. \& GIARDINA, M. 2013. Analysis of operator human errors in hydrogen refuelling stations: Comparison between human rate assessment techniques. International Journal of Hydrogen Energy, 38, 1166-1176.

ČEPIN, M. 2008. DEPEND-HRA-A method for consideration of dependency in human reliability analysis. Reliability Engineering \& System Safety, 93, 1452-1460.

DAVOUDIAN, K., WU, J.-S. \& APOSTOLAKIS, G. 1994. Incorporating organizational factors into risk assessment through the analysis of work processes. Reliability Engineering \& System Safety, 45, 85-105.

DE FELICE, F., PETRILlO, A., CARlOMUSTO, A. \& RAMONDO, A. 2012. Human Reliability Analysis: A review of the state of the art. IRACST-International Journal of Research in Management \& Technology (IJRMT), 2.

DE GALIZIA, A., DUVAL, C., SERDET, E., WEBER, P., SIMON, C. \& IUNG, B. Advanced investigation of HRA methods for probabilistic assessment of human barriers efficiency in complex systems for a given organisational and environmental context. International Topical Meeting on Probabilistic Safety Assessment and Analysis, PSA 2015, 2015.

DEACON, T., AMYOTTE, P., KHAN, F. \& MACKINNON, S. 2013. A framework for human error analysis of offshore evacuations. Safety Science, 51, 319-327.

DHILLON, B. 1989. Human errors: a review. Microelectronics Reliability, 29, 299-304.

EMBREY, D., KONTOGIANNIS, T. \& GREEN, M. 1994. Guidelines for reducing human error in process operations. New York: Centre for Chemical Process Safety.

FONSECA, R. A., ALVIM, A. C. M., FRUTUOSO E MELO, P. F. F. \& ALVARENGA, M. A. B. 2013. A THERP/ATHEANA Analysis of the Latent Operator Error in Leaving EFW Valves Closed in the TMI-2 Accident. Science and Technology of Nuclear Installations, 2013. GROTH, K. M. \& SWILER, L. P. 2013. Bridging the gap between HRA research and HRA practice: A Bayesian network version of SPAR-H. Reliability Engineering \& System Safety, 115, 33-42.

HOLLNAGEL, E. 1998. Cognitive reliability and error analysis method (CREAM), Elsevier. 
KIM, M. C., SEONG, P. H. \& HOLLNAGEL, E. 2006. A probabilistic approach for determining the control mode in CREAM. Reliability Engineering \& System Safety, 91, 191199.

KIRWAN, B. 1992. Human error identification in human reliability assessment. Part 2: Detailed comparison of techniques. Applied ergonomics, 23, 371-381.

KIRWAN, B. 1994. A guide to practical human reliability assessment, CRC press.

KIRWAN, B. 1996. The validation of three Human Reliability Quantification techniquesTHERP, HEART and JHEDI: Part 1-technique descriptions and validation issues. Applied ergonomics, 27, 359-373.

KIRWAN, B. 1997. The validation of three human reliability quantification techniquesTHERP, HEART and JHEDI: part iii-Practical aspects of the usage of the techniques. Applied Ergonomics, 28, 27-39.

KIRWAN, B. \& AINSWORTH, L. K. 1992. A guide to task analysis: the task analysis working group, CRC press.

KONSTANDINIDOU, M., NIVOLIANITOU, Z., KIRANOUDIS, C. \& MARKATOS, N. 2006. A fuzzy modeling application of CREAM methodology for human reliability analysis. Reliability Engineering \& System Safety, 91, 706-716.

KORB, K. B. \& NICHOLSON, A. E. 2010. Bayesian artificial intelligence, CRC press.

LEE, C.-J. \& LEE, K. J. 2006. Application of Bayesian network to the probabilistic risk assessment of nuclear waste disposal. Reliability Engineering \& System Safety, 91, 515-532.

LYONS, M., ADAMS, S., WOLOSHYNOWYCH, M. \& VINCENT, C. 2004. Human reliability analysis in healthcare: a review of techniques. International Journal of Risk \& Safety in Medicine, 16, 223-237.

MANNAN, S. 2012. Lees' Loss prevention in the process industries: Hazard identification, assessment and control, Butterworth-Heinemann.

MARQUEZ, D., NEIL, M. \& FENTON, N. 2010. Improved reliability modeling using Bayesian networks and dynamic discretization. Reliability Engineering \& System Safety, 95, 412-425.

MCLEOD, R. W. 2015. Designing for Human Reliability: Human Factors Engineering in the Oil, Gas, and Process Industries, Gulf Professional Publishing.

MEYER, M. A. \& BOOKER, J. M. 2001. Eliciting and analyzing expert judgment: a practical guide, SIAM.

MIHAJLOVIC, V. \& PETKOVIC, M. 2001. Dynamic bayesian networks: A state of the art.

MOIENI, P., SPURGIN, A. \& SINGH, A. 1994. Advances in human reliability analysis methodology. Part I: Frameworks, models and data. Reliability Engineering \& System Safety, 44, 27-55.

NOROOZI, A., KHAKZAD, N., KHAN, F., MACKINNON, S. \& ABBASSI, R. 2013. The role of human error in risk analysis: Application to pre-and post-maintenance procedures of process facilities. Reliability Engineering \& System Safety, 119, 251-258.

PARK, K. S. 1987. Fuzzy apportionment of system reliability. Reliability, IEEE Transactions on, 36, 129-132.

PARK, K. S. \& JUNG, K. T. 1996. Considering performance shaping factors in situationspecific human error probabilities. International Journal of Industrial Ergonomics, 18, 325331.

PODOFILLINI, L., DANG, V., ZIO, E., BARALDI, P. \& LIBRIZZI, M. 2010. Using expert models in human reliability analysis - a dependence assessment method based on fuzzy logic. Risk analysis, 30, 1277-1297.

RAOUF, A., DUFFUAA, S., BEN-DAYA, M., DHILLON, B. \& LIU, Y. 2006. Human error in maintenance: a review. Journal of Quality in Maintenance Engineering, 12, 21-36. 
SINGH, S. \& KUMAR, R. 2015. Evaluation of Human Error Probability of Disc Brake Unit Assembly and Wheel Set Maintenance of Railway Bogie. Procedia Manufacturing, 3, 30413048.

SWAIN, A. D. 1990. Human reliability analysis: Need, status, trends and limitations. Reliability Engineering \& System Safety, 29, 301-313.

SWAIN, A. D. \& GUTTMANN, H. E. 1983. Handbook of human-reliability analysis with emphasis on nuclear power plant applications. Final report. Sandia National Labs., Albuquerque, NM (USA).

TAYLOR-ADAMS, S. \& KIRWAN, B. 1997. Human reliability data requirements. Disaster Prevention and Management: An International Journal, 6, 318-335.

TRUCCO, P., CAGNO, E., RUGGERI, F. \& GRANDE, O. 2008. A Bayesian Belief Network modelling of organisational factors in risk analysis: A case study in maritime transportation. Reliability Engineering \& System Safety, 93, 845-856.

WATSON, I. 1985. Review of human factors in reliability and risk assessment. The Assessment and control of major hazards, 323-337.

WEBER, P., MEDINA-OLIVA, G., SIMON, C. \& IUNG, B. 2012. Overview on Bayesian networks applications for dependability, risk analysis and maintenance areas. Engineering Applications of Artificial Intelligence, 25, 671-682.

WILLIAMS, J. A data-based method for assessing and reducing human error to improve operational performance. Human Factors and Power Plants, 1988., Conference Record for 1988 IEEE Fourth Conference on, 1988. IEEE, 436-450.

WILLIAMSON, J. 2004. Bayesian nets and causality: philosophical and computational foundations.

ZIO, E., BARALDI, P., LIBRIZZI, M., PODOFILLINI, L. \& DANG, V. N. 2009. A fuzzy setbased approach for modeling dependence among human errors. Fuzzy Sets and Systems, 160, 1947-1964. 